\title{
O PAPEL DAS NOVAS TECNOLOGIAS NA MATERIALIZAÇÃO DO ACESSO À JUSTIÇA EM TEMPOS DE CRISE: ENTRAVES E PERSPECTIVAS
}

\author{
José Laurindo de Souza Netto * \\ Karen Paiva Hippertt ${ }^{* *}$ \\ Adriane Garcel ${ }^{* * *}$
}

\begin{abstract}
RESUMO
O trabalho objetiva ampliar o espaço para a discussão e refletir sobre o papel das novas tecnologias na materialização do acesso à justiça em tempos de crise. A problemática reside em investigar as tecnologias que estão a serviço da Justiça e o seu papel, particularmente, em um mundo contemporâneo pós-pandêmico. Examinar até que ponto sua adoção contribuí para a materialização do substancial do direito fundamental e, também, representa óbice à sua salvaguarda, limites e perspectivas. Como resposta a problemática proposta, evidenciou-se o papel determinante das iniciativas de modernização, com inserção de novas tecnologias e adequação da jurisdição aos novos tempos.

Palavras-chave: Pandemia; Acesso à Justiça; Direito Fundamental; Materialização; Novas tecnologias; Inteligência Artificial; Sexta onda; Judiciário; Projetos.

\section{THE ROLE OF NEW TECHNOLOGIES IN MATERIALIZING ACCESS TO JUSTICE IN TIMES OF CRISIS: OBSTACLES AND PERSPECTIVES}

\begin{abstract}
The work aims to expand the space for discussion and reflect on the role of new technologies in materializing access to justice in times of crisis. The problem is investigating how
\end{abstract}

\footnotetext{
* Doutor e Mestre pela Universidade Federal do Paraná. Estágio de Pós-doutorado pela Faculdade de Direito da Universidade Degli Studi di Roma La Sapienza. Professor de direito processual no curso de mestrado da Universidade Paranaense - UNIPAR. Professor convidado do Programa de Mestrado e Doutorado do Centro Universitário Curitiba - UNICUIRITBA. Desembargador Presidente do Tribunal de Justiça do Estado do Paraná. E-mail: professorlaurindojln@gmail.com. Lattes: http://lattes.cnpq.br/8509259358093260. ORCID: http://orcild .org/0000-0002-6950-6128.

*** Mestranda no Programa de Mestrado em Direito Empresarial e Cidadania, no Centro Universitário Curitiba. Pós-graduanda em Direito Constitucional pela Academia Brasileira de Direito Constitucional. Especialista em Processo Civil, Mediação e Arbitragem pela Pontifícia Universidade Católica do Paraná. Graduada em Direito pela Pontifícia Universidade Católica do Paraná - Curitiba. Assessora da Presidência do Tribunal de Justiça do Estado do Paraná. E-mail: karen.hippertt@ gmail.com. Lattes: http://lattes.cnpq.br/5863810703081925. ORCID: http://orcid.org/0000-0002-3991-8850.

**** Mestra em Direito Empresarial e Cidadania pelo Centro Univiersitário Curitiba - UNICURITIBA. Pósgraduada em Direito Público Aplicado pela Escola da Magistratura do Paraná - EMAP. Pós-graduada em Direito do Trabalho, Processo do Trabalho e Previdenciário pela Escola da Magistratura do Trabalho da $9^{a}$ Região EMATRA/Centro Universitário UNIBRASIL.Pós-Graduada em Ministério Público, especialista em Estado Democrático de Direito pela Fundação Escola do Ministério Público - FEMPAR/ UNIVERSIDADE POSITIVO. Graduação em Letras com licenciatura Plena em Português e Inglês pelo Centro Universitário Campos de Andrade. Graduação em Direito pela Universidade Tuiuti do Paraná. Advogada licenciada na OAB/PR. Mediadora Judicial. Assessora Jurídica da Presidência do Tribunal de Justiça do Estado do Paraná. E-mail: adriane.garcel@tjpr.jus.br. Lattes: http://lattes.cnpq.br/3684019694966209. ORCID: http://orcid.org/000000025096-9982.
} 
technologies are at the service of Justice and their role, particularly in a contemporary postpandemic world. Examination to what extent its adoption contributes to the materialization of the fundamental right and,also, represents an obstacle to its salvation, limits and limits. In response to the proposed problem, the decisive role of modernization initiatives was highlighted, with the insertion of new technologies and adaptation of the jurisdiction to new times.

Keywords: Pandemic; Access to justice; Fundamental right; Materialization; New technologies; Artificial intelligence; Sixth wave; Judiciary; Projects.

\section{INTRODUÇÃO}

O acesso à justiça é pressuposto do Estado de Direito, porquanto a salvaguarda de todas as demais garantias previstas no ordenamento está intimamente relacionada à sua materialização.

Entretanto, o direito fundamental disposto no art. $5^{\circ}$, inciso XXXV, da Constituição Federal, não corresponde à simples garantia de acessar o Judiciário para ter "his day in Court".

Àquilo que Tartuce intitulou de mote do pleno acesso de todos à justiça, inclusive, foi o que causou a crise do Judiciário. Os dados não deixam mentir, o Brasil conta com número recorde de um processo para cada duas pessoas.

Mesmo com uma produtividade crescente, o Judiciário não dá conta do número acentuado de demandas que se multiplicam dia a dia em proporções geométricas. É o que demonstra o relatório Justiça em Número elaborado pelo CNJ, referente ao ano-base de 2020.

Em verdade, para além do acesso meramente formal, a garantia fundamental representa o direito fundamental à efetiva e substancial prestação da justiça, que impõe a adoção de uma série de ações e medidas para a concretização do direito de forma ótima.

De outro vértice, na sociedade do Big Data, o desenvolvimento tecnológico tem, em todos os aspectos, impactado significativamente a vida das pessoas, acelerando, trazendo eficiência, conferindo melhor desempenho as mais diversas atividades.

No Judiciário, às atividades podem ser facilmente realizadas por um algoritmo em tempo muito inferior atribuindo maior velocidade e melhor desempenho.

Para além, se antes da pandemia já eram muitos os desafios postos ao Judiciário contemporâneo, em um mundo pós-pandêmico, complexo, efêmero e marcado por imparáveis demandas acrescidas às 80 milhões em trâmite, a discussão em torno da implementação e desenvolvimento das novas tecnologias em todas as etapas do processo torna-se inevitável.

Assim, o presente estudo tem por objetivo investigar as tecnologias à serviço da Justiça e o seu papel na universalização do acesso à justiça, particularmente, em um mundo contemporâneo pós-pandêmico. Mais especificamente, examinar até que ponto sua adoção contribuí para a materialização do direito fundamental e, também, representa óbice à salvaguarda - limites e perspectivas.

Partindo destas reflexões, a exposição se desenvolverá em três capítulos, para além da introdução e conclusão. Abordar-se-á, primeiramente, a questão do acesso à justiça, buscando compreender sua conceituação e entraves à materialização, as chamadas ondas renovatórias do acesso à justiça, para, na sequência, investigar as novas tecnologias. Por fim, adentrar-se-á no cerne da problemática do presente estudo analisando o papel das tecnologias na materialização do acesso à justiça, entraves e perspectivas. Para a elaboração, será 
utilizado o método lógico dedutivo combinado aos precedentes de pesquisa bibliográfica e documental.

O estudo do tema se justifica em razão do momento histórico. Se antes a inserção das tecnologias era objeto de pautas de reuniões incansáveis no Judiciário, cada vez mais se farão instrumentos imprescindíveis.

\section{ACESSO À JUSTIÇA}

$\mathrm{O}$ acesso à justiça é garantia constitucional fundamental expressamente contemplada no art. $5^{\circ}$, XXXIV e XXXV, da Constituição Federal, art. $10^{\circ}$ da Declaração Universal dos Direitos do Homem, art. $6^{\circ}$ da Convenção Europeia dos Direitos do Homem e, ainda, no artigo $3^{\circ}$ do Código de Processo Civil, enquanto princípio geral estruturante do processo.

Reconhecidamente, a conceituação do direito não é tarefa fácil, considerando a sua multidimensionalidade e transformação salutar ao longo da história, variando conjuntamente com o tecido social de cada época, instituições e condições de vida de cada povo (SOUZA NETTO; CARDOSO, 2013, p. 69 - 90, 2013).

Nos Estados liberais burgueses, por exemplo, o acesso à justiça correspondia ao direito formal de interpor, demandar e defender-se (CAPPELLETTI; GARTH, 1988, p. 9), a clássica conceituação de Liberman de acesso irrestrito ao judiciário.

Hodiernamente, diante da superação da filosofia positiva da sociedade do laissezfaire, o princípio da inafastabilidade do controle jurisdicional, ou direito de ação, como também é conhecido, passou a representar mecanismo essencial à proteção efetiva, concretização e exercício de todos os demais direitos, demandando atuação positiva substancial do Estado (MARMELSTEIN, 2019, p. 297).

Aliás, é por ser pressuposto de todos os demais direitos que, necessariamente, corresponderão a sua persecução, concreção e otimização, que a garantia corresponde a um dos maiores subterfúgios do Estado de Direito.

Para Capelleti (1988, p. 12), a temática é questão central do direito processual contemporâneo e seu estudo "[...] pressupõe um alargamento e aprofundamento dos objetivos e métodos da moderna ciência jurídica".

Em sentido amplo, o acesso à justiça corresponde à inafastabilidade do controle jurisdicional, vedada a edição de leis que excluam da apreciação do Judiciário lesão ou ameaça a direito.

Nada obstante, o direito não é assim tão simplório, não se limita à perspectiva formal da simples instauração de um processo, "[...] possibilitando que o cidadão tenha his day in Court, na sugestiva denominação da Suprema Corte americana. Vai muito mais além" (MARMELSTEIN, 2019, p. 297). Especificamente, impõe “[...] a busca permanente de um modelo ideal de processo, que seria aquele processo justo, adequado, transparente, rápido, barato, simples, efetivo e democrático" (MARMELSTEIN, 2019, p. 297).

Aliás, na década de 70 , do século $\mathrm{XX}$, foi justamente o conceito excessivamente alargado e formalista de acesso ajustiça, dentro daquilo que Tartuce (2016) intitula mote do pleno acesso de todos à justiça, que deu lugar ao que se tem hoje por crise da justiça.

$\mathrm{Na}$ atualidade, a garantia do acesso à jurisdição está mais afeita à exigência de um aperfeiçoamento da prestação da tutela jurisdicional com a exigência de adequação, celeridade e efetividade de modo universal. 
Para Salomão (2016), de fato, trata-se de uma das grandes conquistas da Constituição que rompe a lógica do puro e simples acesso formal, representado pela possibilidade de ajuizamento de demandas no Judiciário, para antes compreender " [...] a entrada e saída em um processo justo e adequado à solução do conflito" (SALOMÃO, 2016).

Nestes termos, falar em acesso à justiça significa assegurar nada menos do que um acesso extremamente adequado com obtenção de solução tempestiva e bastante ajustada ao tipo de lide (SALOMÃO, 2016), conceito este resultante da compreensão contemporânea do acesso à justiça enquanto direito fundamental à efetiva prestação da justiça.

Conforme adverte Uadi Lammêgo Bulos (2007, p. 482), a garantia passa a mensagem de que " [...] todo homem, independente de raça, credo, condição econômica, posição política ou social, tem o direito de ser ouvido por um tribunal independente e imparcial, na defesa de seu patrimônio ou liberdade.".

Nesta seara, verifica-se que a garantia " [...] serve para determinar duas finalidades básicas do sistema jurídico: proporcionar acesso igualitário a todos e produzir resultados individual e socialmente justos" (CAPPELLETTI, 1994, p. 71).

Dito isto, a problemática que se instaura em torno do tema é que a universalização do direito não é assim tão simples.

No mundo da vida, diversos são os percalços a se superar e que envolvem inúmeros pressupostos, em sua maioria, extrajurídicos, foi o que constataram Cappelletti, Garth (1988) e Kim Economides (1999) em seus estudos.

Após longa investigação, que resultou na obra "O Acesso à justiça", Cappelletti e Garth evidenciaram três obstáculos existentes para que o acesso à justiça abrangesse a todos indistintamente, vislumbrando a necessidade de que perpassasse por três ondas renovatórias.

Com início em 1965, a primeira onda renovatória decorre da constatação de que o valor elevado dos honorários, custas processuais e falta de informação, somados ao formalismo nas relações jurídicas e serviços do Judiciário, representam barreiras ao acesso dos mais pobres à justiça, tornando-se essencial assegurar a gratuidade de justiça. A primeira onda tem por enfoque a implementação de modelos jurídicos que prestem assistência aos mais necessitados, como é o caso, no Brasil, da Defensoria Pública e da Lei 1.060/1950.

Em meio à vigência de um processo originariamente de cunho individualista, a segunda onda, por seu turno, decorre da constatação da ausência de uma sistemática processual com mecanismos aptos à tutela dos direitos difusos e coletivos. Neste sentido, destacam-se o Código de Defesa do Consumidor, Ação Popular, Ação Civil Pública e o Mandado de Segurança Coletivo.

$\mathrm{Na}$ terceira onda, intitulada por Cappelletti e Garth de "o enfoque do acesso à justiça”, a problemática é analisada de modo mais amplo, constatando-se a necessidade de aprimoramento da prestação da tutela jurisdicional com desburocratização da justiça e adoção de mecanismos outros pelo Estado que proporcionem acessibilidade, celeridade e maior adequação. A terceira onda evidencia o papel dos Juizados especiais que abriu às portas aos casos menos complexos com adoção em maior medida dos métodos adequados de resolução de conflitos (SILVERIO, 2008). Aliás, o objetivo por de traz da terceira onda é justamente a superação do paradigma vigente de resolução de conflitos, inovando e reestruturando os modelos usuais.

Para além, Kim Economides investiga a problemática a partir de uma nova ótica, direcionando o foco de sua investigação para a oferta dos serviços jurídicos, ao constar que por de traz de sua natureza e estilo há obstáculos que devem ser removidos para a melhoria da prestação jurisdicional e salvaguarda do acesso à justiça. 
Conforme salienta Barros, Teodoro e Maia (2015, p. 31 - 45) "O foco central desta vez se divide em duas esferas, a primeira sobre o acesso dos cidadãos ao ensino do direito e ao ingresso nas profissões jurídicas; e em segundo, como estes operadores, uma vez investidos nas carreiras, teriam acesso à justiça, ou seja, como estariam preparados para fazer justiça". Será que os prestadores dos serviços jurídicos estariam preparados para representarem as diversas das demandas jurídicas? Que “ [...] tipo de cultura jurídica está sendo formada? (...) o profissional formado hoje em dia está preparado para enfrentar um judiciário lento e cheio de burocracia? Os currículos universitários correspondem a uma boa formação humanística?" (SIQUEIRA, 2010).

Neste contexto, a quarta onda renovatória proposta pelo autor direciona-se à questão epistemológica do direito, com o ponto central de investigação redirecionado do acesso para a Justiça e a capacitação dos operadores do direito. A quarta onda tem por marco a efetivação da EC 80/2014 que concentra atenção nos grupos marginalizados.

A despeito disso, a problemática da universalização do acesso à justiça é tão multifacetada que, até os dias atuais, diversos estudos se dedicam ao tema.

O projeto Global Access to Justice (ORGANIZAÇÃO DAS NAÇÕES UNIDAS), desenvolvido por um grande grupo de especialistas globais, das mais diversas profissões e culturas, tem investigado a temática de forma pioneira levantando a necessidade de mais três ondas.

Destarte, a quinta, sexta e sétima ondas levantadas pelo estudo correspondem, respectivamente, ao processo de internacionalização da proteção dos direitos humanos, iniciativas promissoras e novas tecnologias para o aprimoramento da justiça, bem como a desigualdade de gênero e raça nos sistemas de justiça.

O presente estudo tem por objeto de investigação tão somente as novas tecnologias na Justiça, investigando o seu papel na universalização do acesso à justiça, particularmente, no âmbito do Judiciário.

A pandemia, inclusive, tem sido indicada como evento propulsor da tendência global de adoção de novas tecnologias na era conhecida como Big Data. É o que destaca Luis Felipe Salomão (2020): "O impacto da tecnologia já era o grande motor para as mudanças que estão acontecendo interna e externamente ao Judiciário. Com a pandemia isso se acelerou, ganhou dinâmica própria".

Mesmo antes do reabrir das portas do Judiciário, será latente a necessidade de discussão em torno da adoção das tecnologias pioneiras e seu papel na Justiça. Com a reabertura, as novas tecnologias passarão a ser o braço direito na retomada do país pelo Judiciário no pós-pandemia (HIPPERTT; COSTA CASTRO; DE SOUZA NETTO, 2020, p. $39-40)$.

\section{TECNOLOGIAS A SERVIÇO DA JUSTIÇA}

Na sociedade do Big Data, o desenvolvimento tecnológico tem, em todos os aspectos, impactado significativamente a vida das pessoas.

Se por um lado a tecnologia acelera, traz eficiência e melhor desempenho às mais diversas atividades, por outro, as intensas transformações que acarreta impõem nova pauta de discussão em torno dos seus reflexos.

No Big Data jurídico do Judiciário, marcado pela intensa geração de dados em grande velocidade, a situação não foi diferente. A tecnologia diluiu fronteiras e foi para muito além da mera troca da máquina de escrever pelos editores de textos eletrônicos. 
A digitalização dos processos, com a Lei 11.419/2006, foi o grande primeiro passo para a redução da burocracia necessária ao andamento e gestão dos processos, que se tornou um ônus elevado aos padrões de eficiência da prestação jurisdicional.

Antes disso, dois terços do período total de tramitação das ações de rito ordinário compreendiam o chamado "tempo morto do processo", tempo total destinado a atividades burocráticas para gerenciamento e andamento do processo físico, juntada, carimbo, encadernamento, vistas, movimentações físicas, conclusões, retorno das conclusões, em suma, ao vai e vem do processo. O tempo útil, dedicado às atividades ligadas ao conhecimento, ficava restrito à apenas um terço do tempo (CORDEIRO; BORGES, 2014).

Destarte, em um Judiciário em crise, que não consegue entregar a prestação jurisdicional em tempos e condições adequadas, recorrer a ferramentas tecnológicas que propiciem redução de gastos e aumento de produtividade passou a ser necessidade urgente.

A eliminação do papel, com a implementação do processo eletrônico, foi apenas o primeiro passo.

No século XVII, Leibnitz, uma das figuras centrais da filosofia, já advertia acerca do desperdício de recursos e horas com consultas manuais à jurisprudência.

Os dados levantados pelo relatório Justiça em Número elaborado pelo CNJ, referente ao ano-base de 2019, apontam que, apesar da maior produtividade dos magistrados e servidores de forma coordenada, em ambos os graus de jurisdição, teve-se uma taxa de congestionamento de $68,5 \%$, sendo que a grande maioria destes processos compreendem ações repetitivas com mesma tese jurídica, o que corrobora a imprescindibilidade da mudança, em especial, dado que já não é mais possível aumentar os níveis de eficiência somente com a pura e simples ampliação de pessoal (CNJ, 2020).

$\mathrm{O}$ acréscimo da tecnologia em todas as etapas do processo transforma o Judiciário atribuindo maior velocidade e melhor desempenho.

Devidamente empregado, o universo tecnológico poderá trazer inumeráveis benefícios para o dia a dia do Judiciário brasileiro.

Ato contínuo, a tendência se evidencia diante da acentuada curva de crescimento do mercado voltado à obtenção de soluções tecnológicas para a área jurídica. Em outubro de 2017, no Brasil, existiam 51 legaltechs distribuídas em 8 categorias; em 2019, esse número saltou para 139 com 14 categorias diferentes.

Nesta conjuntura, a necessidade de aperfeiçoamento com adoção de soluções inteligentes é evidente em um país como o Brasil que nos últimos anos passou a contar com o número recorde de um processo para cada dois brasileiros (CARDOSO, 2015) e um orçamento limitado que não suporta a contratação de mais funcionários para a realização de tarefas maçantes que facilmente poderiam ser realizadas em tempo recorde pelas novas tecnologias.

Os softwares de inteligência artificial reduzem em larga escala as atividades repetitivas dos servidores que poderão ter mais tempo para se dedicar a atividades mais complexas.

No Judiciário, por exemplo, atividades burocráticas e repetitivas compreendem a grande parcela das tarefas do quotidiano e poderiam ser facilmente realizadas por um algoritmo em tempo muito inferior.

A inovação, por sua vez, reduziria a necessidade de designar pessoal para a execução destas atividades, deixando espaço para a valorização das tarefas intelectuais.

Particularmente, em se considerando a multiplicação de demandas e o orçamento limitado, investir em tecnologia é saída inteligente para a crise do Judiciário e retomada no 
pós- pandemia. É o que destaca Salomão (2020) ao tratar das medidas a serem adotadas pelo Judiciário quando da reabertura dos Tribunais no pós-pandemia.

Neste contexto, se mesmo antes da pandemia os Tribunais já vinham empregando esforços para virtualizar e modernizar de forma ampla a justiça, com atribuição de acessibilidade, celeridade e economia, dentro do binômio tempo e custo, agora, as iniciativas precisam se intensificar e concretizar.

A Inteligência Artificial (IA), arcabouço de múltiplas tecnologias e conhecimentos de diversas áreas, ciências de dados, linguística, teoria cognitiva, dentre outras, também tem sido utilizada pelo judiciário que nela investiu para fazer frente ao aumento em progressão geométrica das demandas.

Neste sentido, a Portaria n. 25/2019 instituiu o Laboratório de Inovação do Processo Judicial em meio Eletrônico, criando o Pje e o Centro de Inteligência Artificial Aplicada ao PJ.

A portaria, que veio a inaugurar diversas iniciativas sistematizadas pelo Conselho Nacional de Justiça as disponibilizando para todo o Judiciário, é resultado da constatação da “ [...] necessidade que o Poder Judiciário brasileiro tem de oferecer uma resposta adequada a todos àqueles que buscam os serviços de justiça [...]" e acaba por criar um "[...] espaço para pensar, pesquisar e produzir inovação para o processo judicial eletrônico".

Oriunda da Segunda Guerra Mundial, a Inteligência Artificial (IA) é resultado de estudo realizado em 1943 por Warren McCulloch e Walter Pitts, que tem por subterfúgio a fisiologia dos neurônios e suas funções, a lógica proporcional de Russel e Whitehead, bem como a teoria computacional de Turing, que propôs modelo de neurônio artificial e redes definidas de formato compatível, capaz de aprender.

A conceituação do que vem a ser inteligência artificial, contudo, não se mostra assim tão simples. Diversos são os conceitos em torno daquilo que vem a ser inteligência artificial.

Em termos amplos, a IA consiste na "[...] ciência de construção de máquinas que fazem coisas que requeiram inteligência [...]" (OVER, 2001), pensamento racional, que pensam, ou agem, como seres humanos, ou, ainda, racionalmente. Por isso se diz que "A história da inteligência artificial (IA) é caracterizada por uma expansão constante dos aspectos da expertise e cognição humanas para modelos computacionais" (WYPYCH; NETO, 2019, p. $292-294)$.

Para Medina e Martins (2020) a inteligência artificial pode ser entendida como o "[...] desenvolvimento de ferramentas de informática que emulem inteligência humana ou que executem função a ela relacionada, tais como, raciocínio, aprendizagem, adaptabilidade, percepção e interação com o meio físico etc.”.

Aprioristicamente, os estudos ligados ao desenvolvimento da IA tinham por enfoque o plano rotineiro relacionado à aplicação de regras precisas a acontecimentos certos. Hodiernamente, se dedicam a questões mais complexas envolvendo a jurisdição.

Com as novas tecnologias de machine learning (aprendizagem de máquina), deep learning (vertente para aprendizagem de máquinas que incluem várias técnicas para aprendizado, aprendizado por meio de árvore de decisão, programação de lógica indutiva, agrupamento, aprendizagem de reforço, redes bayesianas e etc.), Big Data (mineração de dados), inovação disruptiva e Processamento de Linguagem Natural (estuda soluções de gerenciamento e compreensão automática da linguagem natural, convertendo a informação em linguagem compreensível, ou representação mais fácil de ser manipulada pelos programas computacionais), a inteligência artificial sofreu grandes mudanças ao longo dos últimos anos.

O emprego destas novas tecnologias permitiu o desenvolvimento de sistemas de software inteligentes que, por meio de sua utilização e de um amplo banco de dados, 
aprendem desempenhando as melhores escolhas. É o caso da Siria da Apple, a Alexa da Amazon, a Watson da IBM e, no âmbito jurídico, do VICTOR.

Particularmente, com relação ao VICTOR, o Projeto visa solucionar "[...] a classificação (vinculação) de processos em temas de Repercussão Geral (RG) do Supremo Tribunal Federal. Isto é, [...] um problema de Processamento de Linguagem Natural (PLN), o que especificamente requer o desenvolvimento de um sistema composto por algoritmos de aprendizagem de máquina que viabilize a automação de análises textuais desses processos jurídicos [...]" (SILVA, 2018, p. 89 - 90), facilitando a identificação dos temas relacionados de forma mais precisa e homogênea. Além disso, a inteligência possibilita a classificação dos processos, registro de erros na resposta dos modelos, implementação de modelos de classificação de machine leraning.

Conforme salienta Toffoli $(2018$, p. 89 - 90), dado o sucesso do VICTOR, que reduziu em $60 \%$ o tempo de trâmite das ações, em breve, a tecnologia deverá se estender por todo território nacional, utilizada no primeiro juízo de admissibilidade dos recursos extraordinários, evitando que recursos que tratem de matéria referente à repercussão geral sejam levados ao STF. A iniciativa reduzirá em muito o número de ações.

Além disso, o Superior Tribunal de Justiça criou a Instrução Normativa n. 6/2018 que instituiu projeto-piloto de aplicação de soluções de inteligência artificial no Tribunal.

Também, no âmbito Estadual, os Tribunais têm caminhado neste sentido, a exemplo da criação das Equipes do departamento de Tecnologia da Informação e Comunicação, no Tribunal de Justiça do Paraná, com incumbência de verificar casos mais sofisticados em que a implementação da inteligência artificial se mostrar útil.

Na seara da Justiça Federal, a Associação Nacional dos Delegados da Polícia Federal (ADPF), em parceria com grupo de estudos da Faculdade de Direito do IDP, tem o intuito de desenvolver programas que ajudem no combate à corrupção, fraudes e crimes cibernéticos, realizando leitura e cruzamento de dados, além de auferir o significado de conteúdos.

Igualmente, o CNJ tem encabeçado Projetos de inteligência com o fim de aperfeiçoar o trabalho realizado, são eles, o "Movimento Inteligente", que faz uso de mecanismo de leitura automatizado para classificar o movimento do processo, otimizando a qualidade do cadastramento de peças e documentos processuais, e o "Gerador de Textos", similar aos geradores de texto dos aplicativos que completam automaticamente as sentenças e aprendem de acordo com a rotina do usuário e sua escolha vocabular, projetado às de maior probabilidade (MONTENEGRO, 2019). Atualmente, o robô que se utiliza de redes neurais para sugerir minutas conta com um banco de dados com mais de 44 mil despachos, sentenças e julgamentos (AMARAL, 2020).

As iniciativas compõem o Projeto SINAPSES, elaborado em conjunto pelo CNJ e Tribunal de Justiça de Rondônia, que objetivam integrar inovações no contexto da SINAPSES com o PJe. As ferramentas serão disponibilizadas de forma gratuita e fazem parte da Estratégia Nacional do Poder Judiciário 2015 - 2020 (ENTIC-JUD) de racionalizar o sistema judicial e otimizar os gastos públicos por meio da intensificação do uso da tecnologia da informação.

Outros robôs que têm estado à serviço da Justiça, descongestionando o Judiciário e trazendo assertividade são: (1) o Pôtis, utilizado pelo Tribunal de Justiça do Rio Grande do Norte para a execução fiscal e penhora de bens; (2) o Radar, que auxilia os juízes de primeira instância do Tribunal de Justiça de Minas Gerais na localização e agrupamento das demandas repetitivas, já as pré-definindo; (3) e o Elis, que auxilia à triagem de processos de execução fiscal no Tribunal de Justiça de Minas Gerais, examinando cerca de 80 mil processos, que não seriam analisados em menos de um ano e meio, em cerca de 15 dias (AMARAL, 2020). 
Por sua vez, o Tribunal de Justiça do Rio de Janeiro conta com uma plataforma de negociação que faz uso de chatbot na identificação autônoma de ações de danos coletivos, uma parceria do Núcleo Permanente de Solução de Conflitos do Tribunal com o Ministério Público Estadual (MARANHÃO, 2019).

Veja-se, ainda, que a automação das decisões judiciais utilizadas a serviço da justiça compreendem três diferentes níveis: um nível mais básico, a chamada tecnologia de apoio, utilizada para informar, apoiar, ou aconselhar; um segundo nível, intermediário, tecnologia de substituição, que substitui as funções e atividades dos seres humanos; e, por fim, um terceiro nível, tecnologia disruptiva, com potencial para alterar significativamente o trabalho dos juízes com novos modelos de justiça (MEDINA; DOS PASSOS MARTINS, 2020).

Para Martins (2020), os três níveis de automação das decisões judiciais se dão de acordo com a extensão da aplicação da Inteligência Artificial às decisões.

O primeiro nível, adotado em maior medida pelo Judiciário e que deve continuar a prevalecer até o amadurecimento da IA, corresponde ao emprego da Inteligência para auxiliar a atividade decisória humana, com automação das tarefas burocráticas, repetitivas, básicas, consulta e constrição de bens (BACENJUD, RENAJUD, INFOJUD, SIEL e etc.), triagem de processos, indicação de casos repetitivos, precedentes vinculantes aplicáveis e etc., além de conferir apoio na tomada de decisão com auxílio na pesquisa de jurisprudência e doutrina, apontamento de erros com sugestão de modelos de fundamentação, inclusive, sugerindo préanálise de decisões e minutas de votos. No primeiro nível, ainda há a necessidade de intervenção humana por meio de avaliação e conferencia da legitimidade das tarefas realizadas pela máquina.

O segundo nível, por sua vez, corresponde ao emprego da automação na gestão do processo que será conduzido de forma independente pelo próprio sistema, efetivando atos e despachos mais mecânicos. Diferentemente do primeiro nível, no segundo, dispensa-se a verificação pelo ser humano, que irá centrar sua atividade na elaboração de decisões mais complexas, antecipação de tutela, decisões interlocutórias, saneadores e sentenças.

Ademais, o Portal Atlas, criado em 2013, pelo Conselho Nacional de Justiça e Ordem dos Advogados do Brasil, é outra tecnologia a serviço do acesso à justiça. A ferramenta fornece informações à população de forma sistematizada compreendendo cinco serviços: (1) Mapa da Justiça, que indica a localização dos órgãos e instituições do Sistema de Justiça, inclusive, os trajetos, com disponibilização de mapas; (2) Indicadores Nacionais de Acesso à Justiça, medem o índice de Acesso à Justiça no âmbito Estadual; (3) ABC dos seus direitos, disponibilização de materiais na plataforma no intuito de informar a população à respeito de seus direitos, garantias e como reivindica-los; (4) relatórios e estudos sobre o Sistema de Justiça para difundir conhecimento e informações à população; (5) e consulta de qual órgão possui competência para solucionar a situação, ou conflito, a partir do problema/ situação, ou termo correlato, pesquisados na plataforma pelo usuário (BRASIL, 2014).

Igualmente, muitas instituições ligadas ao sistema de Justiça e o próprio Judiciário têm feito uso das redes sociais, principalmente, perfis no Instagram e Facebook, com o objetivo de produzir conteúdo acessível à população para informá-la acerca dos mais variados temas envolvendo os seus direitos e tornar o sistema de justiça mais acessível.

Em contrapartida, apesar dos avanços proporcionados pelas novas tecnologias, o desenvolvimento embrionário da Inteligência Artificial ainda desperta polêmica no uso da tecnologia na tomada autônoma de decisões judiciais em substituição ao ser humano. Também, é o caso da adoção fragmentária do processo virtual que causa dificuldades de ordem prática, bem como do acesso à justiça dos excluídos digitais, que representam parcela significativa da população. Todas questões advindas do novo normal e que irão preencher a 
pauta de discussão do Judiciário na medida em que às tecnologias vão sendo inseridas nas diversas fases do processo.

\section{O PAPEL DAS TECNOLOGIAS NA MATERIALIZAÇÃO DO ACESSO À JUSTIÇA: ENTRAVES E PERSPECTIVAS}

Em verdade, o direito fundamental ao acesso à justiça perfectibiliza o exercício da própria democracia que se fundamenta na lei e torna-se uma ilusão se não estiver disponível a toda população de forma substancial.

A previsão formal da garantia fundamental de nada adianta se, no mundo dos fatos, ainda houver percalços à sua concretização.

Sobretudo, em uma sociedade contemporânea, a celeuma se agrava em muito. A multiplicação de demandas em progressão geométrica, a litigiosidade imparável, o formalismo excessivo, a adoção incipiente de iniciativas que conferem eficiência e o orçamento limitado fazem da entrega da prestação jurisdicional célere e efetiva árdua missão.

A crise da justiça, inclusive, se vê refletida em pesquisa realizada pela Associação dos Magistrados Brasileiros (apud VIANNA; CARVALHO; BURGOS, 2019) que aponta que boa parte dos magistrados vislumbra na sobrecarga e excesso de formalidades da justiça obstáculos à eficiência na atividade jurisdicional. A pesquisa evidencia, ainda, que os magistrados concentram a maior parte do tempo em atividades repetitivas que poderiam ser facilmente realizadas com uso da Inteligência Artificial.

Antes mesmo da pandemia, os dados da Comissão das Nações Unidas para o Empoderamento Legal dos Pobres apontavam que mais da metade da população mundial está fora da proteção efetiva da lei. São 3,8 bilhões de pessoas vulneráveis, que não podem buscar a tutela de seus direitos no sistema de justiça.

Além disso, os dados do CNJ (BRASIL, 2020) revelam uma taxa de congestionamento 68,5\%. A grande maioria destes processos são ações repetitivas com mesma tese jurídica.

Particularmente, em tempos críticos, complexos e efêmeros, de pandemia e póspandemia, com a multiplicação de demandas acima da média, assegurar acesso substancial à justiça se fará um desafio inigualável.

Deste modo, a superação do modelo tradicional, com adoção de novas tecnologias é fundamental para viabilizar a entrega de uma prestação jurisdicional célere e efetiva.

Conforme afirma Daniel Hillis, co-chairman da Applied Minds, "Os desafios e os problemas que estamos encarando hoje são complexos demais para serem atacados por um único ser humano. Assim, a entidade que vai resolver o problema será uma combinação de humanos e máquinas trabalhando juntos, formando uma espécie de inteligência integrada" (HILLIS, 2014).

As tecnologias, neste sentido, vêm justamente para agilizar e melhorar o trabalho, oferecendo respostas rápidas e assertivas à sociedade. É o que destaca Melo (2017):

O ecossistema da Justiça é uma área em que a Ciência de Dados tem um impacto significativo no auxílio do trabalho intelectual de juízes, advogados, defensores, promotores e procuradores. A Inteligência Artificial, aplicada a um sistema de gestão, pode apoiar o trabalho desses profissionais e ajudá-los a obter insights valiosos que só são possíveis com uma interpretação inteligente da imensa quantidade de dados disponíveis. 
Nesta conjuntura, a automação e a inteligência artificial concretizam transformações profundas e exponenciais que permitirão o enfrentamento dos árduos desafios que já estão postos e que irão se multiplicar no mundo pós-pandemia.

Operações que antes demandavam um setor inteiro passarão a ser feitas de modo mais eficiente, célere e com maior qualidade graças ao uso dos softwares. A tecnologia aumentará a capacidade de analisar grande volume de informações e operar as tarefas em grandes proporções, trará “ [...] consigo o potencial de alavancar enormes transformações nos campos da produtividade e da eficiência operacional [...]" (FLORÃO, 2017, p. 53).

Após a adoção de novas tecnologias que facilitaram a triagem e seleção dos processos, o Superior Tribunal de Justiça diminuiu o número de demandas (BRASIL, 2020); no Supremo Tribunal Federal, o robô VICTOR reduziu em $60 \%$ o tempo de trâmite das ações; e o robô Elis possibilitou a análise de 80 mil processos em 15 dias, no Tribunal de Justiça de Minas Gerais - estes são apenas alguns dos exemplos no âmbito da Justiça.

À vista disso verifica-se que o acréscimo da tecnologia a todas as etapas do processo transforma o Judiciário atribuindo maior velocidade e melhor desempenho.

Ainda assim, a Inteligência Artificial é uma novidade e o seu desenvolvimento incipiente desperta polêmica na tomada autônoma de decisão em substituição ao ser humano.

Em razão disso, torna- se essencial que os Tribunais adicionem os impactos negativos decorrentes às suas agendas de discussões, de modo a evitar as consequências. É o que adverte Martins (2020, p. 38):

\begin{abstract}
Deve-se ter em mente que o uso da Inteligência Artificial na área jurídica ainda é uma novidade, de forma que os sistemas existentes ainda não dispõem de um nível de desenvolvimento e de confiabilidade que permitam dispensar a supervisão humana. Por exemplo, a experiência registra casos em que os sistemas de Inteligência Artificial se comportam de forma preconceituosa, além do que há questões relativas à auditabilidade dos resultados produzidos por redes neurais artificiais, empregadas em sistemas de machine learning. Nessas circunstâncias, a manutenção do ser humano no controle das decisões confere um certo conforto moral para os jurisdicionados e para a sociedade como um todo, em que pese os julgadores humanos também possam falhar.
\end{abstract}

Por este motivo, ao menos a curto e médio prazo, o emprego da Inteligência Artificial nos Tribunais deverá se dar de forma conjunta com o trabalho humano, reunindo-se aptidões, ambos se complementando nos pontos em que se sobressaem (MEDINA; DOS PASSOS MARTINS, 2020).

Os “ $[\ldots]$ computadores serão capazes de guardar mais informações [...], além de identificar teses jurídicas predominantes pelos tribunais em menor tempo [...]" (ATHENIENSE, 2018). Por sua vez, seres humanos se destacam no “ [...] senso comum, moral, imaginação, abstração, dilemas, sonhos, generalização [...]” (ATHENIENSE, 2018). Desta forma, a adoção da máquina não dispensará a verificação do julgador com relação ao trabalho autonomamente realizado, às advertências de possíveis erros serem negligenciados.

As Orientações Técnicas da União Europeia para uma Inteligência Artificial de Confiança, inclusive, revelam a supervisão enquanto requisito essencial à sedimentação de uma IA confiável, viabilizada a via recursal, com mecanismos para revisão da decisão tomada pela máquina.

Além da automação e da inteligência artificial, o uso de plataformas de comunicação digital, tais como, criação de perfis no Instagram, ou Facebook, por parte da Defensoria Pública, Ministério Público e Tribunais, tem sido essencial para desburocratizar o acesso à justiça.

Revista Cidadania e Acesso a Justiça | e-ISSN: 2526-026X | Encontro Virtual | v. 7 | n. 2 |

p. $19-35$ | Jul/Dez. 2021. 
Acessíveis a toda a população, os perfis trazem informações úteis de forma simplificada acerca dos mais variados temas envolvendo o sistema de justiça, métodos adequados de resolução de conflitos, direitos, garantias, como reivindica-los, funcionamento da justiça e etc., um verdadeiro exercício de educação em direitos. De certo modo, a iniciativa se assemelha ao Portal Atlas, criado em 2013, já que ambos fazem uso da informação acessível para democratizar o acesso à justiça.

Por fim, apesar de o processo eletrônico ter sido importante passo, o excesso de plataformas é um entrave.

Atualmente, tem-se mais de 40 plataformas usadas pelos mais de 90 tribunais e cada uma delas funciona melhor em um determinado programa de navegação (Mozilla Firefox, Internet Explorer, ou Google Chrome) (GRILLO, 2017). Ainda, há tribunais que têm mais de um sistema funcionando ao mesmo tempo. Os tribunais do Paraná e de Roraima, por exemplo, usam simultaneamente o Pje e o Projudi. O Tribunal do Rio Grande do Norte, por seu turno, se utiliza do Pje e do e- SAJ.

Também, há aqueles que alteram seus sistemas, antes mesmo de a plataforma ter sido implementada em todas as comarcas, uma verdadeira salada mista que gera prejuízos enormes ao trabalho do advogado e, consequentemente, à parte.

Somado a isso, conforme adverte Cesar Orlando (2017), fundador da LegalCloud, diante de uma "[...] alteração de grande magnitude no Judiciário, todos os sistemas precisarão se adaptar, o que implica em maiores custos e tempo de migração [...]", em completo desacordo com a ideia de acesso à justiça eficiente.

Não obstante, a tarefa de unificar todo o sistema não se mostra assim tão simples do ponto de vista prático. A melhor saída para a promoção de resultados mais céleres à Justiça seria investir na "[...] disponibilização de interfaces de integração entre os sistemas dos tribunais, outras instituições, e escritórios de advocacia - aliada a um portal único nacional de peticionamento e consultas aos advogados que não possuem sistemas informatizados [...]" (GRILLO, 2017).

Ainda assim, o processo eletrônico foi importante passo, já que não apenas dispensou o papel, mas também proporcionou agilidade e economia na prestação da tutela jurisdicional. Ganhou- se tempo, celeridade, diminui-se burocracia e ampliou-se, ou no mínimo facilitouse, o acesso à Justiça.

Em verdade, nos dias de hoje, há que se reconhecer que o sucesso da jurisdição e, consequente, salvaguarda do acesso substancial à justiça, está intimamente relacionado com a operacionalização do Judiciário através de mecanismos de gestão. Por isso, as iniciativas voltadas à modernização, adequando à jurisdição as transformações sociais, se fazem essenciais (JACOBSEN; BATISTA, 2013).

Somado a isso, em um Judiciário cada vez mais digital o acesso à justiça dos excluídos digitais também é questão a se pensar. Tratam-se de cerca de 45,960 milhões de pessoas (IBGE, 2020) com dificuldades de acesso ao novo normal tecnológico.

Para uma justiça inclusiva, plural e universal a tecnologia deverá ser guarnecida com o desenvolvimento de política de atenção aos excluídos digitais, de forma que não tenham sua desigualdade acentuada, ficando em zona de penumbra no sistema, com seus direitos fundamentais silenciosamente violados. É preciso uma atenção especial, também, a esta pauta, nos moldes do que prevê a Recomendação 101/2021 do Conselho Nacional de Justiça, se preciso, indo além, de modo que possam usufruir dos benefícios inerentes a um Judiciário tecnológico sem que o novo normal represente mais um percalço ao efetivo acesso à justiça deste grupo vulnerável. 
Por conclusão, tem-se que o sucesso da jurisdição, com acesso substancial à justiça, está intimamente relacionado à operacionalização do Judiciário por intermédio de mecanismos de gestão.

\section{CONCLUSÃO}

O acesso à justiça é um dos direitos e garantias mais importante da pessoa humana, porquanto essencial à proteção efetiva de todos os demais direitos.

Para longe de um acesso meramente formal a corte, a garantia impõe uma atuação positiva e substancial do Estado na "busca permanente de um modelo ideal de processo, [...] justo, adequado, transparente, rápido, barato, simples, efetivo e democrático" (MARMELSTEIN, 2019, p. 297).

Em seus estudos, Cappelleti, Garth (1988) e Economides (1999, p. 67) já haviam constatado a necessidade de o acesso passar por quatro ondas para tornar-se factível a toda a população de modo substancial. Assistência judiciária gratuita, tutela adequada dos direitos da coletividade, métodos adequados de resolução de conflitos, desburocratização da justiça e formação adequada dos operadores do direito — os primeiros passos à resolução da problemática.

Recentemente, o projeto Global Access to Justice (ORGANIZAÇÃO DAS NAÇÕES UNIDAS) levantou a necessidade de mais seis ondas, destacando o papel das novas tecnologias no aprimoramento do acesso à justiça.

Especialmente, em tempos de pandemia, com a multiplicação imparável de demandas, dentro do contexto de um Judiciário em crise que há muito não consegue dar conta da entrega de uma prestação jurisdicional substancial, as novas tecnologias passarão a ser o braço direito na retomada do país pelo Judiciário.

Apesar de os desafios da contemporaneidade por si só já imporem a discussão em torno do tema, a pandemia acelerou o processo, não deixando alternativa outra.

As novas tecnologias subsidiam a construção de uma Justiça mais moderna, eficiente, ágil, rápida e substancial. Concretizam transformações profundas e exponenciais que irão permitir à materialização em ótima medida do acesso à justiça, mesmo diante dos árduos desafios postos e que irão surgir no "novo normal" do mundo pós-pandemia.

Os resultados têm sido excelentes, o potencial é enorme, mas o caminho a trilhar ainda é longo. Trata-se de uma novidade cujo desenvolvimento, ao menos, a princípio, não dispensará a verificação humana da atividade desenvolvida.

Destarte, não se pode perder de vista os impactos negativos oriundos da adoção destes novos mecanismos. Necessariamente, os Tribunais devem adicionar os impactos negativos às agendas de discussões.

\section{REFERÊNCIAS}

AMARAL, Camila. Você conhece todos os robôs que já operam no Judiciário brasileiro? migalhas.com.br, 27 mar. 2020. Disponível em: https://www.migalhas.com.br/depeso/3 22824/voce-conhece-todos-os-robos-que-ja-operam-no-judiciario-brasileiro. Acesso em: 13 jan. 2021.

ATHENIENSE, Alexandre Rodrigues. As premissas para alavancar os projetos de inteligênci a artificial na justiça brasileira. Revista de Direito e as Novas Tecnologias, v. 1, out.-dez. 20 18. Revista dos Tribunais Online. 
BARROS, Flaviane Magalhães; TEODORO, Warlen Soares; MAIA, Amanda Monique de Souza Aguiar. Primeiras linhas para acesso ao processo. Revista do Direito Público, v. 10, n. 1, p. 31-45, 2015.

BRASIL. Conselho Nacional de Justiça. Justiça em Números 2020: ano-base 2019. Brasília: CNJ, 2020. Disponível em: https://www.cnj.jus.br/pesquisas-judiciarias/justica-em-numeros/. Acesso em: 17 out. 2020.

BRASIL. Conselho Nacional de Justiça. Portaria no 25 de 19/02/2019. Disponível em: http://www.cnj.jus.br/atos-normativos?documento=2829. Acesso em: 20 ago. 2020.

BRASIL. Ministério da Justiça e Segurança Pública. Confira o Atlas do Acesso à Justiça no Brasil. justica.gov.br, 17 fev. 2014. Disponível em: https://legado.justica.gov.br/news/conf ira-o-atlas-do-acesso-a-justica-no-brasil-1. Acesso em: 19 ago. 2020.

BRASIL. Superior Tribunal de Justiça. Presidente do STJ destaca importância da inteligência artificial na gestão e no planejamento da Justiça. stj.jus.br, 2 jul. 2020, 13:50. Disponível em: http://www.stj.jus.br/sites/portalp/Paginas/. Acesso em: 1 fev. 2021.

BULOS, Uadi Lammêgo. Curso de direito constitucional. São Paulo: Saraiva, 2007, p. 482.

CARDOSO, Maurício. Brasil atinge a marca de 100 milhões de processos em tramitação na Justiça. conjur.com.br, 15 set. 2015, 15:00. Disponível em: https://www.conjur.com.br/2015 -set-15/brasil-atinge-marca-100-milhoes-processos-tramitacao. Acesso em: 1 fev. 2021.

CAPPELLETTI, Mauro. La dimensione sociali: l'acesso alla giustizia. Dimensioni della giustizia nella società contemporanee. Bolonha: Il Mulino, 1994, p. 71 e ss.

CAPPELLETTI, Mauro; GARTH, Bryant. Acesso à justiça. Tradução de Ellen Gracie Northfleet. Porto Alegre: Fabris, 1988, p. 9.

DE SOUZA NETTO, José Laurindo; CARDOSO, Cassiana Rufato. A Jurisdição Constitucional como instrumento potencializador da efetividade dos Direitos Humanos. Revista da Escola da Magistratura do Paraná. Ed. Especial Comemorativa de 30 anos. Curitiba: LedZe, p. 69-90, 2013.

DE SOUZA NETTO, José Laurindo; FOGAÇA, Anderson Ricardo; HIPPERTT, Karen Paiva; GARCEL, Adriane. Estado de Direito e o Acesso à Justiça em uma Sociedade PósPandemia: o Papel das Escolas Formadoras na Construção da Magistratura do Futuro. In: III

CONIBADEC - Congresso Ibero Americano de Direito Empresarial e Cidadania, 2020, Curitiba. Anais do III CONIBADEC - Congresso Ibero Americano de Direito Empresarial e Cidadania, 2020. v. 03. p. 83-92.

ECONOMIDES, Kim. Lendo as ondas do "Movimento de Acesso à Justiça": epistemo logia versus metodologia?. p. 67. Disponível em: //gajop.org.br/justicacidada/wpcontent/upl oads/Lendo-as-Ondas-do-Movimento-de-Acesso-aa-Justica.pdf. Acesso em: 25 mai. 2020. 
FERNANDES, Ricardo Vieira de Carvalho; CARVALHO, Angelo Gamba Prata de Coord. Tecnologia jurídica \& direito digital: II Congresso Internacional de Direito, Governo e Tec nologia - 2018. Belo Horizonte: Fórum, 2018. pp. 89-90.

FLORÃO, Marcos. Coragem de ser humano - o desafio da computação cognitiva pode revolucionar a Justiça brasileira. Revista Fonte, Minas Gerais: n. 17, jul. 2017, p. 53. Disponível em: Comunicacao/Noticias/02072020-Presidente-do-STJ-destaca-importanciadainteligencia-artificial-na-gestao-e-no-planejamento-da-Justica.aspx. Acesso em: 20 ago. 2020.

GRILLO, Brenno. Excesso de plataformas de processo eletrônico atrapalha advogados. conjur.com.br, 3 out. 2017, 7:30. Disponível em: https://www.conjur.com.br/2017out03/excesso-sistemas-processo-eletronico-atrapalham-advogados. Acesso em: 20 ago. 2020.

HILLIS, Daniel. The Future of Cognitive Computing. youtube.com, 13 jan. 2014. Disponível em: https://www.youtube.com/watch?v=YRdeFdiBjHM. Acesso em: 20 ago. 2020.

HIPPERTT, Karen Paiva; COSTA CASTRO, José Fabiano da; DE SOUZA NETTO, José Laurindo de. Acesso à justiça no pós-pandemia: uma nova onda no Brasil?. In: II Encontro Virtual do CONPEDI, 2020, Florianópolis. Acesso à justiça e solução de conflitos I, 2020. p. $39-40$.

INSTITUTO BRASILEIRO DE GEOGRAFIA E ESTATÍSTICA. Uso da internet, televisão e celular no Brasil. Educa.ibge.gov.br. Disponível em: educa.ibge.gov.br. Acesso em: 30 set. 2021.

JACOBSEN, Gilson; BATISTA, Lazzari. PJe é conjunto de ideias que amplia acesso à Justiça. conjur.com.br, 20 jun. 2013, 8h30. Disponível em:

https://www.conjur.com.br/2013jun-20/processo-eletronico-conjunto-ideias-amplia-acessojustica. Acesso em: 20 ago. 2020.

MARANHÃO, Juliano. Uso de inteligência artificial no Judiciário requer planejamento. conjur.com.br, 17 fev. 2019, 7:40. Disponível em: conjur.com.br/2019-fev-

17/julianomaranhao-uso-ia-judiciario-requer-

planejamento\#: :text=A\%20automação\%20de\%20tare

fas\%20típicas,pelo\%20emprego\%20de\%20inteligência\%20artificial. Acesso em: 20 ago. 2020.

MARMELSTEIN, George. Curso de direitos fundamentais. 8. ed. rev. atual. São Paulo: Atlas, 2019.

MARTINS, João Paulo Nery dos Passos. Inteligência artificial aplicada à atividade jurisdicional. Orientador: José Miguel Garcia Medina. 2020, 144 f. Dissertação (Mestrado em Direito Processual e Cidadania) - Universidade Paranaense - UNIPAR, Umuarama, 2020. p. 38. 
MEDINA, José Miguel Garcia; DOS PASSOS MARTINS, João Paulo Nery. A era da inteligência artificial: as máquinas poderão tomar decisões Judiciais?. Revista dos Tribunais| v. 1020, 2020.

MELO, 2017 apud InSAJ. Tecnologia na Justiça: como a Inteligência Artificial e a Computação Cognitiva estão impactando a área. insaj.jusbrasil.com.br, 2017. Disponível em: https://insaj.jusbrasil.com.br/artigos/466573042/tecnologia-na-justica-comoainteligencia-artificial-e-a-computacao-cognitiva-estao-impactando-a-area. Acesso em: 20 ago. 2020.

MONTENEGRO, Manuel Carlos. BRICS: CNJ apresenta inteligência artificial em processos eletrônicos. cnj.jus.br, 30 out. 2019. Disponível em: https://www.cnj.jus.br/bricscnjapresenta-inteligencia-artificial-em-processos-eletronicos/. Acesso em: 20 ago. 2020.

ORGANIZAÇÃO DAS NAÇÕES UNIDAS. In: PATERSON, Alan et al (Coord.). Global Access to Justice. Disponível em: http://globalaccesstojustice.com/?lang=pt-br. Acesso em: 2 ago. 2020.

OVER, Aires José. Informática no Direito. Inteligência Artificial. Curitiba: Juruá, 2001.

SALOMÃO, Luis Felipe. Mediação e arbitragem são saída para congestionamento processual. conjur.com.br, 19 jun. 2016, 14:00. Disponível em: https://www.conjur.com.br/2016jun19/salomao-mediacao-arbitragem-sao-saida-alta-litigiosidade. Acesso em: 4 jun.2020.

SALOMÃO, Luis Felipe. Temos que achatar a curva das demandas - Ministro do STJ Luis Felipe Salomão. youtube.com, 13 mai. 2020. Disponível em: https://www.youtube.com/wat ch?v=kGInf8pYRPs\&feature=emb_logo. Acesso em: 2 jun. 2020.

SILVERIO, Karina Peres. Acesso á Justiça. ETIC- Encontro Toledo de Iniciação Científica - ISSN 21-76-8498, v. 4, n. 4, 2008. Disponível em: http://intertemas.unitoledo.br/revista/in dex.php/ETIC/article/viewFile/1673/1590. Acesso em: 11 jun. 2016.

SIQUEIRA, Márcio Araújo de. Acesso à Justiça uma realidade ou uma fantasia?. Âmbito Jurídico, Rio Grande, a. 13, n. 75, abr. 2010. Disponível em: http://www.ambitojuridico.com. br/site/index.php?n_link=revista_artigos_leitura\&artigo_id=7479. Acesso em: 26 out. 2020.

TARTUCE, Flávio. O Novo CPC e o Direito Civil. 2. ed. rev., atual. Rio de Janeiro: Forense; São Paulo: MÉTODO, 2016.

TOFFOLI, Dias. Prefácio. In: FERNANDES, Ricardo Vieira de Carvalho; CARVALHO, Angelo Gamba Prata de Coord. Tecnologia Jurídica e Direito Digital: II Congresso Internacional de Direito, Governo e Tecnologia - 2018. Belo Horizonte: Editora Fórum Ltda, 2018. p. 89-90.

VIANNA, Luiz Werneck; CARVALHO, Maria Alice Rezende de; BURGOS, Marcelo Baumann. Quem somos: a magistratura que queremos. Rio de Janeiro: Associação dos Magistrados Brasileiros (AMB), 2018. Disponível em: 
https://www.amb.com.br/wpcontent/uploads/2019/02/Pesquisa_completa.pdf. Acesso em: 16 jun. 2020.

WATANABE, Kazuo. Modalidade de mediação. Série cadernos do CEJ, v. 22, p. 43-50, 2003.

WYPYCH, Ricardo. NETO, Miguel Kfouri. Inteligência Artificial no Judiciário brasileiro: a construção de um modelo para efetivação de direitos e garantias individuais. Percurso, v. 3, n. 30, p. 292-294, 2019. 